\title{
Classification of facial peri-implant soft tissue dehiscence/deficiencies at single implant sites in the esthetic zone
}

\section{Giovanni Zucchelli $^{1}$ ｜ Lorenzo Tavelli $^{2}$ iD | Martina Stefanini $^{1}$ | Shayan Barootchi $^{2}$ (iD | Claudio Mazzotti ${ }^{1}$ ～Guido Gori ${ }^{3}$ ｜ Hom-Lay Wang ${ }^{2}$ iD}

${ }^{1}$ Department of Biomedical and Neuromotor Sciences, University of Bologna,

Bologna, Italy

${ }^{2}$ Department of Periodontics \& Oral Medicine, School of Dentistry, University of Michigan, Ann Arbor, MI, USA

${ }^{3}$ Private practice, Rome, Italy

\section{Correspondence}

Prof. Hom-Lay Wang, DDS, MS, PhD,

Department of Periodontics and Oral

Medicine, University of Michigan School of Dentistry, 1011 North University Avenue, Ann Arbor, MI 48109-1078.

Email:homlay@umich.edu

\begin{abstract}
Background: The incidence of a peri-implant soft tissue dehiscence/deficiency (PSTD) is not a rare finding. Despite multiple previous attempts aimed at correcting the PSTDs, a classification of these conditions has not yet been proposed. This lack in the literature may also lead to discrepancies in the reported treatment outcomes and thus misinform the clinician or the readers. The aim of the present article was therefore to present a classification of peri-implant PSTD at a single implant site.

Methods: Four classes of PSTDs were discussed based on the position of the gingival margin of the implant-supported crown in relation to the homologous natural tooth. In addition, the bucco-lingual position of the implant head was also taken into consideration. Each class was further subdivided based on the height of the anatomical papillae.
\end{abstract}

Results: Subsequently, for each respective category a surgical approach (including bilaminar techniques, the combined prosthetic-surgical approach or soft tissue augmentation with a submerged healing) was also suggested.

Conclusion: This paper provides a new classification system for describing PSTDs at single implant sites, with the appropriate recommended treatment protocol.

\section{K E Y W O R D S}

buccal mucosa, classification, connective tissue, dental implant, esthetics, implant-supported dental prosthesis

\section{1 | INTRODUCTION}

The predictability of dental implants in replacing missing teeth has been extensively demonstrated. ${ }^{1,2}$ The success in implant therapy, however, should not be solely dependent on its long-term survival, but also on its functional, esthetic, hard- and soft-tissue stability, as well as patient-reported outcomes. ${ }^{3,4}$ Indeed, over the years patients' esthetic demands have increased such that even a minimal apical shift of the gingival margin revealing the greyish color of the implant may be considered unacceptable, especially in the esthetic region. ${ }^{5}$
An apical shift of the peri-implant facial soft tissue margin has been defined with many terms throughout the literature, including mid-facial recession, mucosal recession or dehiscence, soft-tissue dehiscence/deficiency or a softtissue defect. ${ }^{6}$ As these complications can manifest either as mucosal recessions (apical shifting of the peri-implant mucosal margin), or only a greyish hue noticeable through the mucosa, and/or discrepancies in the length of the implantsupported crown (compared with the homologous natural tooth), the term peri-implant soft tissue dehiscence/deficiency (PSTD) may be the most appropriate for their description. ${ }^{6}$ 
Regarding its prevalence, a peri-implant PSTD is not a rare finding. In a 2-year prospective study, Bengazi et al. reported a $57 \%$ incidence of PSTD $\geq 1 \mathrm{~mm}$ (on the facial or lingual sites) during the first 6 months. Interestingly, the authors found no further progression in the following months. ${ }^{7}$ Small and Tarnow, based on a noticeable trend of PSTD occurrence in 1 year, concluded that $1 \mathrm{~mm}$ of PSTD can be expected within 3 months from the implant-abutment connection. ${ }^{8}$

Among the factors that can lead to a mucosal recession, Lin et al. proposed that lack of or a minimal keratinized mucosa around implants may play a crucial role. ${ }^{9}$ According to a systematic review by Chen and Buser, immediately placed implants are associated with a higher risk of facial PSTD (from $9 \%$ to $41 \%$ ), ${ }^{10}$ possibly due to the insufficient experience of the surgeon or (site specific) anatomical limitations. ${ }^{11,12}$ In this view, Evans and Chen also discovered a significantly greater apical shift of the soft tissue margin in patients with a thin biotype. ${ }^{13}$ Additionally, they also highlighted the importance of the position of the implant shoulder, which correlated with a three times greater risk of producing PSTD if buccally placed, compared with a lingually positioned one. ${ }^{13}$ Cosyn and colleagues, in line with the previous finding, discovered an odds ratio of 17.2 for mid-facial PSTD and a buccally positioned implant. ${ }^{14}$

The relatively high prevalence of a midfacial PSTD that can range up to $64 \%$ in immediate implants, ${ }^{15}$ can be attributed to many predisposing and precipitating factors including: a buccally positioned implant, an osseous dehiscence or fenestration at the buccal bone, a thin gingival biotype, a lack of or a minimal keratinized mucosa, vigorous tooth brushing, inflammation, and an over contoured prosthesis. ${ }^{16}$ While some of these factors are also present in the case of gingival recessions around natural teeth, ${ }^{16}$ for PSTD to occur around implants it is believed that among all the predisposing factors, the buccolingual positioning of the fixture is the most crucial causative factor. $^{13,14}$

The peri-implant mucosa also significantly differs from the periodontal soft tissue. Indeed, the long junctional epithelium, the parallel organization of the connective tissue fibers, the lower number of fibroblasts, and reduced vascularity which are characteristic of the peri-implant soft tissue, are more similar to a scar tissue than the soft tissue around teeth. ${ }^{17,18}$ These anatomical differences may lead to an inferior PSTD coverage compared with the outcomes usually obtained when treating teeth with the same technique. ${ }^{19}$

Therefore, a classification of PSTDs around implants cannot be based on the conventional methods used for grading gingival recessions. ${ }^{20,21}$ Indeed, a PSTD should not only be defined based on the interproximal attachment level, ${ }^{21}$ rather the position and the extension of the PSTD, the height of the papillae, and the level of the implant-supported crown margin in relation to the contralateral or adjacent teeth and the bucco-lingual position of the implant should also be taken into account.

The primary aim of treating PSTD should include the complete coverage of the dehiscence along with the reestablishment of the soft tissue margin (and the crown margin) at the same level of the homologous tooth. ${ }^{6}$ Many techniques, such as the coronally advanced flap (CAF), ${ }^{19,22}$ the tunnel, ${ }^{23}$ the VISTA technique, ${ }^{24}$ free gingival grafts, ${ }^{25}$ guided bone regeneration procedures, ${ }^{26}$ resubmergence technique, ${ }^{27,28}$ or a surgical-prosthetic approach ${ }^{29}$ have been proposed for treating PSTDs.

It may be reasonable to assume that the variability in the obtained outcomes, such as a vast difference in mean PSTD coverage (from $40 \%$ to $66 \%$ in some trial, ${ }^{19,22}$ to $90 \%$ to $96 \%$ in others ${ }^{5,29}$ ) does not only depend on the surgical approach, but also on the case selection. Thus, it is crucial to presurgically differentiate the types of PSTDs introducing a classification of these conditions.

\section{2 | MATERIALS AND METHODS}

\section{1 | Proposed classification of peri-implant soft tissue dehiscence/deficiencies}

The proposed classification focuses on PSTDs on the facial site of a single implant in the esthetic zone (excluded molar teeth) not affected by peri-implant diseases, with an attempt to suggest a decision-making process for selecting the most appropriate treatment protocol to achieve an ideal esthetic outcome. In agreement with the 2017 World Workshop, ${ }^{30}$ in the absence of baseline radiographs, implants showing signs of inflammation on gentle probing, probing depth $\geq 6 \mathrm{~mm}$, and bone levels $\geq 3 \mathrm{~mm}$ apical of the most coronal portion of the intra-osseous part of the implant are considered to be affected by a peri-implant disease and therefore are excluded from the present classification. However, in the presence of previous examination data, a peri-implant disease is defined based on presence of bleeding on probing, increasing probing depth compared with previous examinations, and the presence of radiographic bone loss beyond crestal bone level changes resulting from initial remodeling. ${ }^{30}$

Hence, the following classification of PSTD was formulated:

- Class I. The soft tissue margin is located in an esthetically correct position (at the same level of the ideal position of the gingival margin of the homologous natural tooth), and the color of the abutment/implant is visible only through the mucosa and/or there is a lack of keratinized tissue/soft tissue thickness (Figs. 1A through 1C)

- Class II. The soft tissue margin is located more apical to the ideal position of the gingival margin of the 

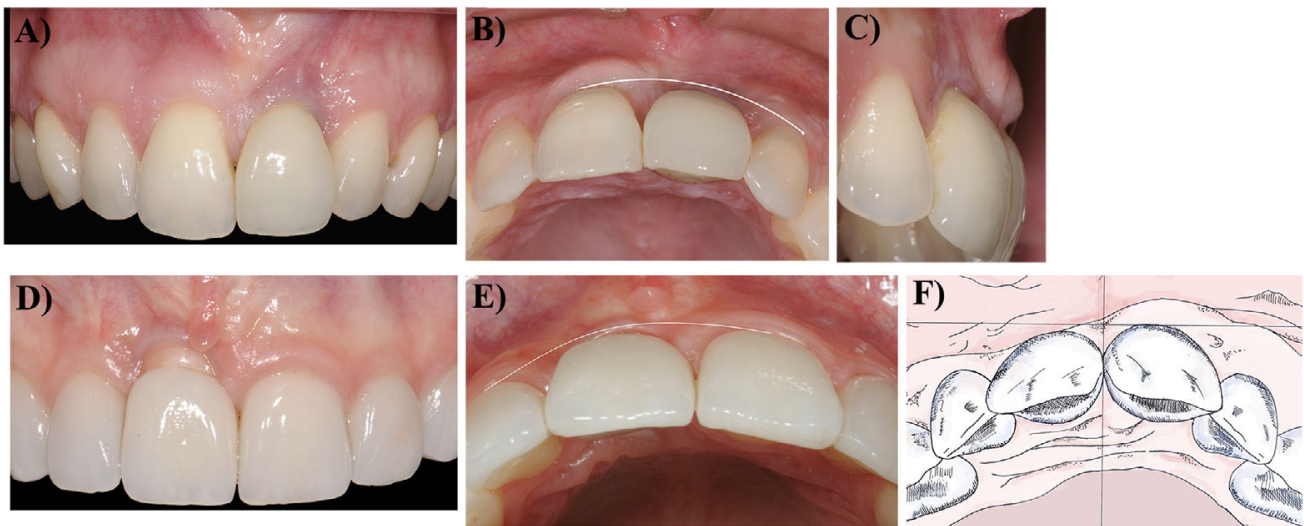

F I G U R E 1 A Frontal, B occlusal, and C lateral view of PSTD Class I. This class is characterized by an esthetically correct position of the soft tissue margin which is at the same level of the gingival margin of the homologous natural tooth, however the color of the abutment/implant is visible through the mucosa. D Frontal, $\mathbf{E}$ occlusal view, and $\mathbf{F}$, schematic drawings of PSTD Class II. This class is characterized by a soft tissue margin which is located more apical to the ideal position of the gingival margin and the implant-supported crown profile is located inside the imaginary curve line that connects the profile of the adjacent teeth at the level of the soft tissue margin

homologous natural tooth and the implant-supported crown profile is located inside (more palatal) the imaginary curve line that connects the profile of the adjacent teeth at the level of the soft tissue margin (Figs. 1D through 1F)

- Class III and IV. The soft tissue margin is located more apical to the ideal position of the gingival margin of the homologous natural tooth and the implant-supported crown profile is located outside (more facial to) the imaginary curve line that connects the profile of the adjacent teeth at the level of the soft tissue margin. In these classes it is mandatory to remove the implant-supported crown. When the head of the implant is inside (more palatal or at the level of) the straight imaginary line that connects the profile of the adjacent teeth at the level of the gingival margin, the PSTD is defined as Class III (Fig. 2), while when the implant head is outside (more facial) this imaginary line, this is referred to as Class IV (Fig. 3).

Each of the classes (except for Class I where subgroup c is not clinically detectable) can be further subdivided into the following subcategories in relation to the papilla dimension:

- a: when the tip of both papillae is $\geq 3 \mathrm{~mm}$ coronal to the ideal position of soft tissue margin of the implant-supported crown (Fig. 4A)

- $\mathrm{b}$ : when the tip of at least one papilla is at a distance $<3 \mathrm{~mm}$ coronal to the ideal position of the soft tissue margin of the implant supported crown (Fig. 4B).

- $\mathrm{c}$ : when the height of at least one papilla is at the same level or more apical of the ideal position of the soft tissue margin of the implant-supported crown (Fig. 4C).

Table 1 depicts the proposed classification of PSTD.

\section{3 | RESULTS}

\section{1 | Recommended treatment protocol for each PSTD type}

A summary of the treatment approaches proposed in the literature for the management of PSTD and their reported outcomes is depicted in Supplementary Data S1 in online Journal of Periodontology.

A PSTD of Class I is not a deficiency in the apico-coronal dimension but in the thickness/amount of keratinized mucosa that allows for the appearance of the greyish color of the implant components. In presence of adequate papillae dimension, a CAF or a tunnel procedure with the addition of a connective tissue graft (CTG) or soft tissue substitutes (e.g., dermal matrix) is therefore the treatment of choice for managing this condition. If one papilla is $<3 \mathrm{~mm}$ in height (subclass b), it is recommended to remove the implantsupported crown and modify the abutment to increase the interproximal soft tissue and therefore increase the vascular supply for the CAF + CTG. A PSTD of Class I subgroup $\mathrm{c}$ is not clinically detectable.

A Class II PSTD can be treated with CAF + CTG when the tips of both papillae are at least $3 \mathrm{~mm}$ in height (subclass a), since this condition is crucial for allowing flap advancement. In this class it is not necessary to remove the implantsupported crown.

While in a Class II, if at least one papilla is $<3 \mathrm{~mm}$ in height (subclass b), it is necessary to remove the implant-supported crown, modify/change the abutment in order to improve the weak papilla and a combined prosthetic-surgical approach is recommended ${ }^{29}$ (Fig. 5).

When the height of at least one papilla is at the same level of or more apical to the ideal position of the soft tissue margin of the implant-supported crown (subclass c), the implant 

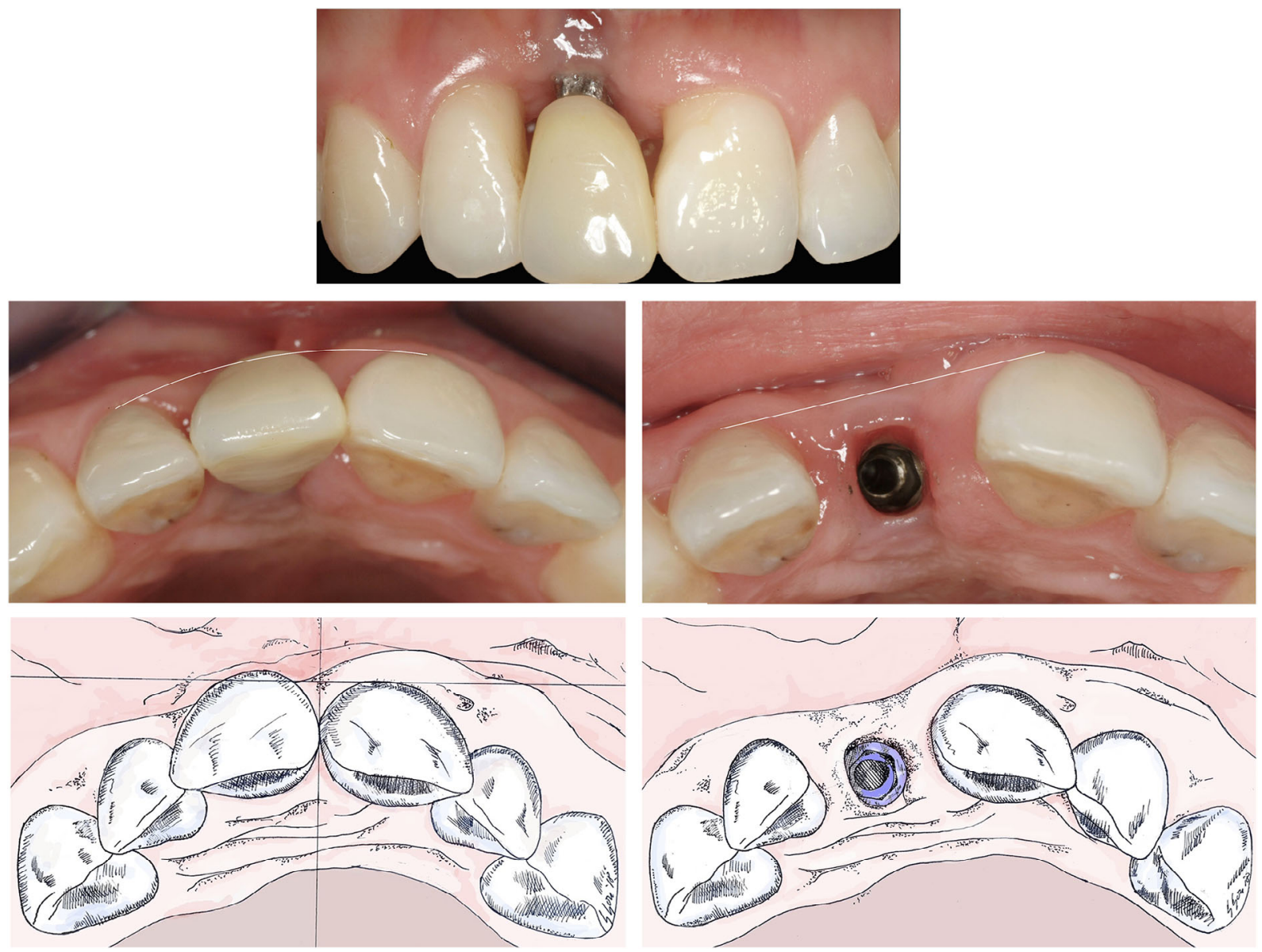

F I G U R E 2 Frontal (top), occlusal view (middle), and schematic drawings (before and after crown removal) (bottom) of PSTD class III. This class is characterized by a soft tissue margin which is located more apical to the ideal position of the gingival margin and the implant-supported crown profile is located outside the imaginary curve line that connects the profile of the adjacent teeth at the level of the soft tissue margin. In addition, the head of the implant, evaluated after crown removal, is inside the straight imaginary line that connects the profile of the adjacent teeth at the level of the gingival margin

supported crown must be removed, a healing cap must be applied, and a soft tissue augmentation procedure with a submerged healing is recommended.

Given the position of the papillae that allow for flap advancement and coronal suturing, Class IIIa can be treated with CAF + CTG after implant supported crown removal without the need to change the abutment and wait for the improvement of the papillae.

Conversely, a complete prosthetic-surgical approach is recommended for treating a Class IIIb.

The lack of at least one papilla in Class IIIc requires a soft tissue augmentation procedure with submerged healing.

When sufficient height ( $\geq 3 \mathrm{~mm}$ ) of both papillae is associated with buccal malpositioning of the implant head (Class IV a) a prosthetic surgical approach is suggested.

Finally, a PSTD of Class IVb can be managed with a soft tissue augmentation procedure with a submerged healing, while PSTDs of Class IV c requires implant removal. ${ }^{31}$

Table 1 summarizes the proposal treatment approaches for each PSTD class.

\section{4 | DISCUSSION}

The efficacy of root coverage procedures in treating gingival recessions on natural dentition have been well established. ${ }^{32,33}$ Additionally, the position of the interproximal attachment levels as the main limiting factor in the amount of root coverage that can be achieved, has also been confirmed. ${ }^{21}$

A PSTD around implants differs greatly from a gingival recession on natural teeth. Incorrect implant placement, lack of buccal bone or mucosal thickness, improper case selection for immediate implant placement, and diameter of the implant platform, act as predisposing factors specifically leading to a mucosal recessions on implants. ${ }^{6}$ Additionally, the vascularization and composition of the connective tissue around implants (with fibers parallel to the implant surface) that resembles a scar tissue, ${ }^{18}$ may negatively impact the surgical outcomes. It may be assumed that the etiology of the PSTD along with the peri-implant anatomy are the main reasons for the overall low predictability of the traditional surgical approach for treating these mucosal defects. ${ }^{19,22}$ 


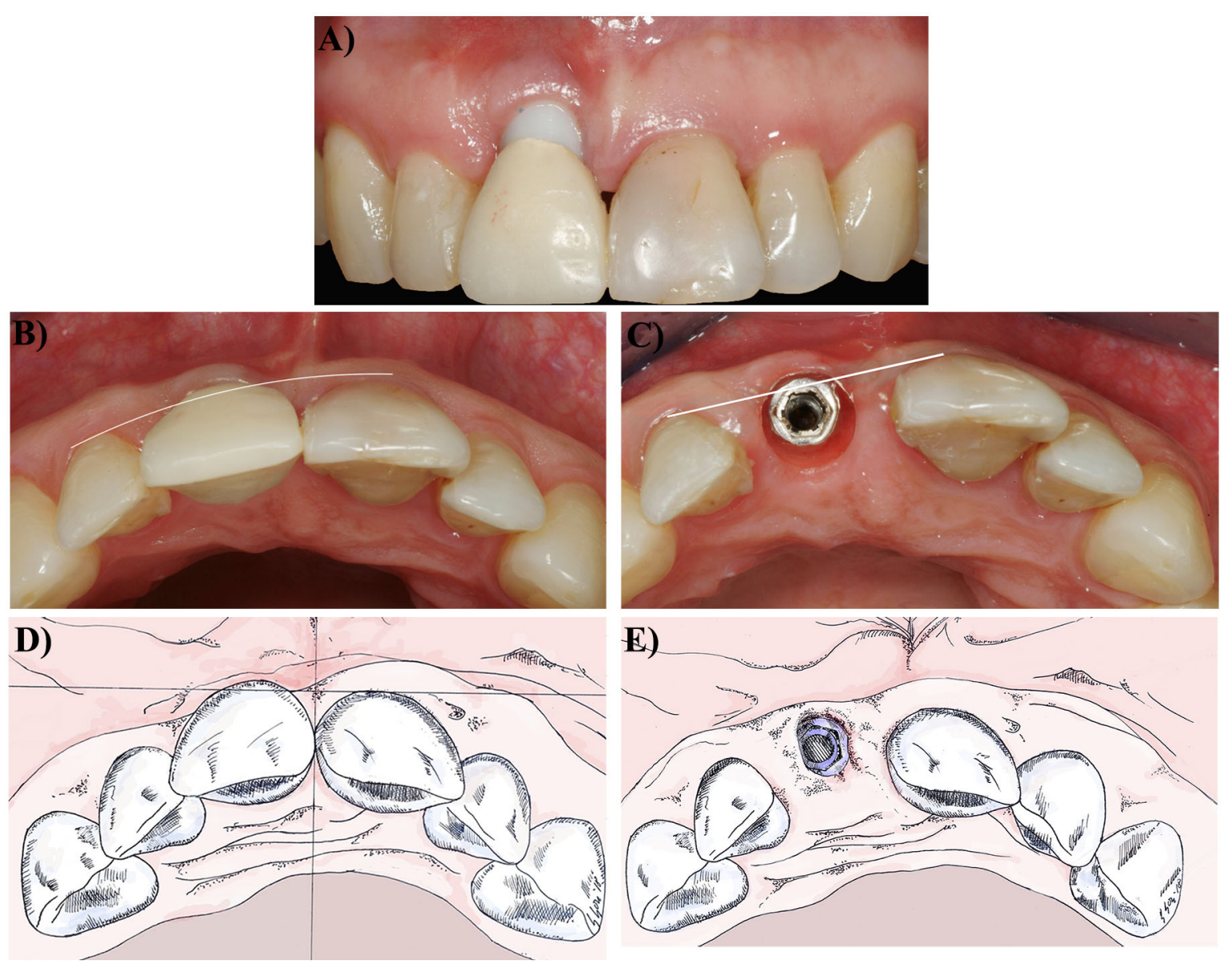

F I G U R E 3 Frontal (A), occlusal view (B and C) and schematic drawings (before and after crown removal) (D and E) of PSTD Class IV. This class has similarities with PSTD Class III in terms of gingival margin position; however the head of the implant, evaluated after crown removal, is outside the straight imaginary line that connects the profile of the adjacent teeth at the level of the gingival margin
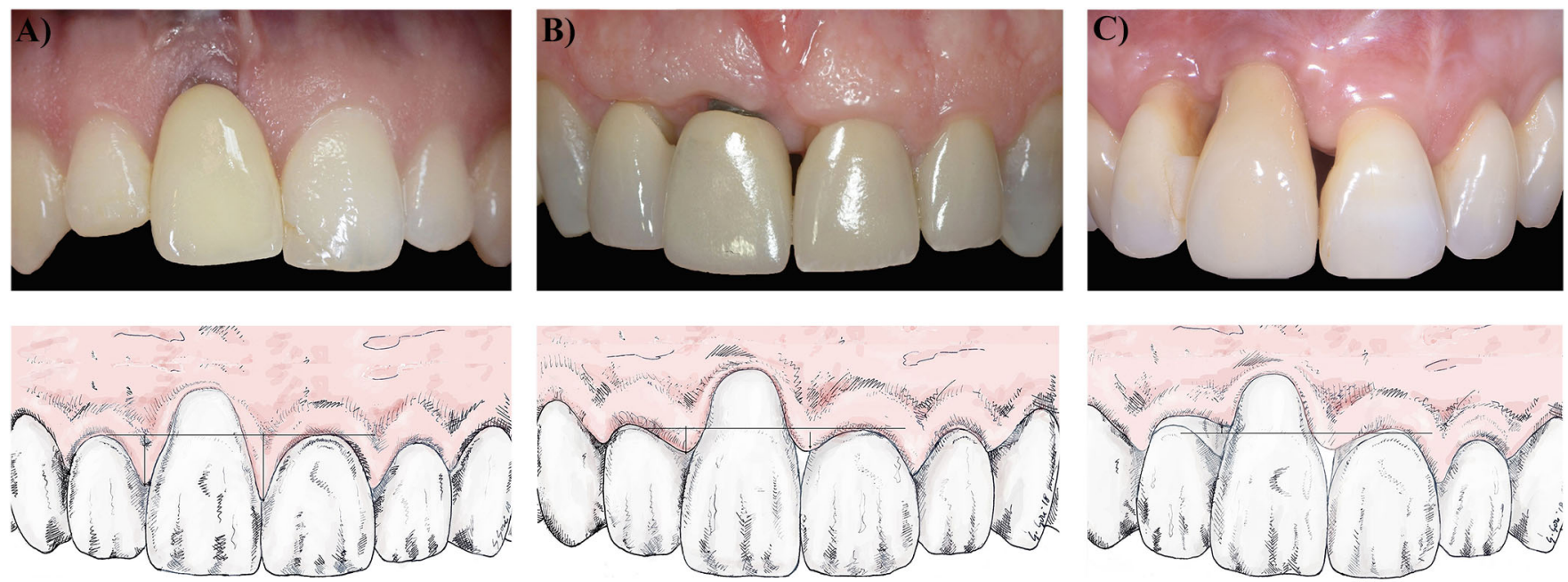

F I G U R E 4 Peri-implant soft tissue dehiscence/deficiency (PSTD) subclasses based on the height of the papillae. A) Subclass a. The tip of both papillae is $\geq 3 \mathrm{~mm}$ coronal to the ideal position of soft tissue margin of the implant-supported crown. B) Subclass b. The tip of at least one papilla is at a distance $<3 \mathrm{~mm}$ coronal to the ideal position of the soft tissue margin of the implant supported crown. C) Subclass c. The height of at least one papilla is at the same level or more apical of the ideal position of the soft tissue margin of the implant-supported crown 
T A B L E 1 Classification of peri-implant soft tissue dehiscence/deficiencies (PSTD) and recommended surgical treatment

\begin{tabular}{|c|c|c|}
\hline Class & Peri-implant soft tissue dehiscence/deficiency characteristics & Recommended surgical treatment \\
\hline I & $\begin{array}{l}\text { The soft tissue margin is located at the same level of the ideal position } \\
\text { of the gingival margin of the homologous natural tooth, and the } \\
\text { color of the abutment/implant is visible only through the mucosa } \\
\text { and/or there is a lack of keratinized tissue/soft tissue thickness }\end{array}$ & $\begin{array}{l}\text { Ia: CAF or tunnel + CTG (or other graft substitutes) } \\
\text { Ib: Combined prosthetic-surgical approach }\end{array}$ \\
\hline II & $\begin{array}{l}\text { The soft tissue margin is located more apical to the ideal position of the } \\
\text { gingival margin of the homologous natural tooth, and the } \\
\text { implant-supported crown profile is located inside (more palatal) the } \\
\text { imaginary curve line that connects the profile of the adjacent teeth at } \\
\text { the level of the soft tissue margin }\end{array}$ & $\begin{array}{l}\text { IIa: No crown removal, CAF + CTG } \\
\text { IIb: Combined prosthetic-surgical approach } \\
\text { IIc: Soft tissue augmentation with submerged } \\
\text { healing }\end{array}$ \\
\hline III & $\begin{array}{l}\text { The soft tissue margin is located more apical to the ideal position of the } \\
\text { gingival margin of the homologous natural tooth } \\
\text { The implant-supported crown profile is located outside (more } \\
\text { facially) the imaginary curve line that connects the profile of the } \\
\text { adjacent teeth at the level of the soft tissue margin, and the head of } \\
\text { the implant (evaluated by removing the crown) is inside (more } \\
\text { palatally) the imaginary straight line connecting the profile of the } \\
\text { adjacent teeth at the level of the soft tissue margin }\end{array}$ & $\begin{array}{l}\text { IIIa: Crown removal, CAF + CTG } \\
\text { IIIb: Combined prosthetic-surgical approach } \\
\text { IIIc: Soft tissue augmentation with submerged } \\
\text { healing }\end{array}$ \\
\hline IV & $\begin{array}{l}\text { The soft tissue margin is located more apical with respect of the ideal } \\
\text { position of the gingival margin of the homologous natural tooth } \\
\text { The implant-supported crown profile is located outside (more } \\
\text { facially) the imaginary curve line that connects the profile of the } \\
\text { adjacent teeth at the level of the soft tissue margin, and the head of } \\
\text { the implant (evaluated by removing the crown) is outside (more } \\
\text { facially) the imaginary straight line connecting the profile of the } \\
\text { adjacent teeth at the level of the soft tissue margin }\end{array}$ & $\begin{array}{l}\text { IVa: Combined prosthetic-surgical approach } \\
\text { IVb: Soft tissue augmentation with submerged } \\
\text { healing } \\
\text { IVc: Implant removal }\end{array}$ \\
\hline \multicolumn{3}{|c|}{ Subclass } \\
\hline
\end{tabular}

*Does not apply for class I PSTD

Given the variety of factors that can cause a PSTD, a thorough pre-operatory case assessment is crucial. However, to date guidelines for defining PSTDs are scarce in the literature. A prognostic classification that included systemic and local factors, as well as implant/host relationship, was proposed by Decker et al. ${ }^{34}$ However, no clinical recommendations in regard to treatment of the PSTDs were provided.

The present classification identifies four classes of PSTDs based on the bucco-lingual position of the crown/implant (except for class I which is characterized by inadequate periimplant keratinized tissue/soft tissue thickness) and three subcategories (for Class II, III, and IV) according to the interproximal papillae dimension. Indeed, recently the quality and the dimensions of the papillae and the bucco-lingual position of the implant have been recognized as key factors affecting the treatment approach. ${ }^{6}$

It should be noted that in Class III and IV, where the crown is located more facially and outside the imaginary line connecting the profile of the adjacent teeth at the level of the soft tissue margin, the position of the implant head must be evaluated. This can only be performed after removing the implantsupported crown, which is a fundamental step in the treatment of such conditions. ${ }^{6}$

A Bilaminar technique ${ }^{35}$ or a tunneling approach ${ }^{23}$ with the implant supported crown in situ, is recommended in treating a Class I PSTD, characterized by the appearance of the implant components underneath the buccal soft tissue. For both techniques a minimal coronal advancement of the flap is indicated to compensate for the space occupied by the graft/substitute material. It has been shown that soft tissue thickness is a crucial factor in discoloration of the mucosa ${ }^{36}$ and that a minimum of $2 \mathrm{~mm}$ in thickness is necessary to mask the greyish color of the implant components. ${ }^{37}$ The gold standard for increasing soft tissue thickness is the autologous CTG. In particular, because of its composition (dense connective tissue rich of collagen fibers with low amount of fatty and glandular tissue) and its characteristics (stability and firmness), the CTG derived from the de-epithelialization of a free gingival graft 

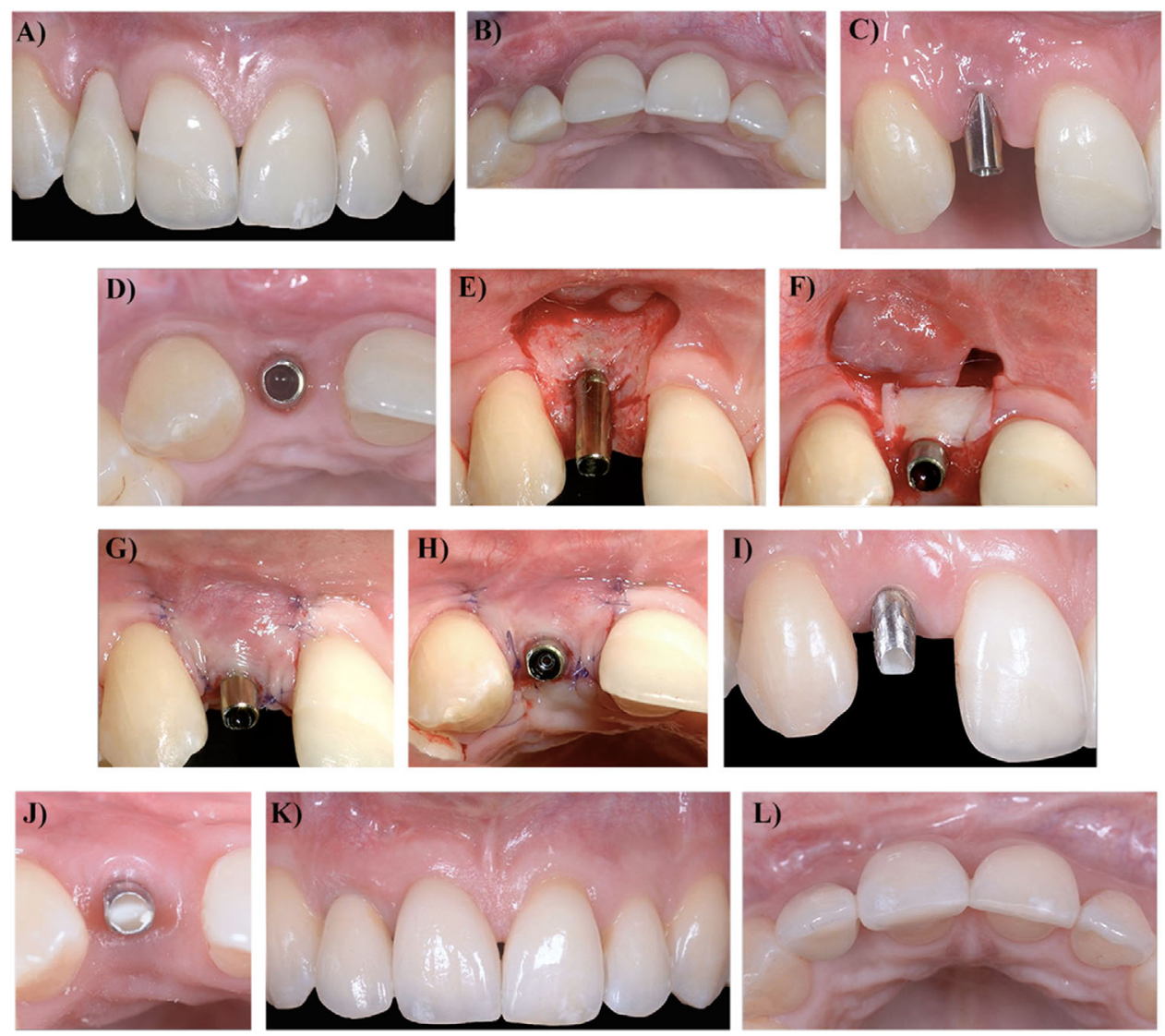

F I G U R E 5 Combined prosthetic-surgical approach for the treatment of a PSTD Class II subclass b. A Baseline frontal and $\mathbf{B}$ occlusal pictures. C Frontal and D, occlusal pictures at the end of the presurgical prosthetic treatment: note the increase of the interproximal soft tissues. Surgical procedure: $\mathbf{E}$ trapezoidal shape flap elevation and $\mathbf{F}$ connective tissue graft (CTG) fixation at the level of the gingival margin of the contralateral homologous tooth. Note the de-epithelialization of the anatomic papillae toward the palatal aspect. G Coronally advanced flap (CAF) closure and $\mathbf{H}$ occlusal pictures showing the primary intention wound closure and the flap adaptation above the abutment convexity. I Frontal and $\mathbf{J}$ occlusal pictures showing soft tissue maturation before conditioning phase. $\mathbf{K}$ Frontal and $\mathbf{L}$ occlusal pictures after definitive restoration demonstrating the complete dehiscence coverage and the increase in soft tissue thickness

can be considered the material of choice. ${ }^{38}$ Alternatively, graft substitutes, such as collagen or acellular dermal matrices have also been used for increasing the tissue thickness with promising results. ${ }^{22,39}$ In the presence of weak papillae, despite the correct position of the gingival margin (Class Ib), increasing the interproximal soft tissue though crown removal and abutment reduction is strongly suggested.

Managing Class II defects, when the tips of both papillae are at least $3 \mathrm{~mm}$ coronal to the ideal position of soft tissue margin of the implant-supported crown (subclass a), CAF + CTG is the treatment of choice, either performed with ${ }^{19,22}$ or without ${ }^{40}$ vertical releasing incisions. In this clinical situation it is even more recommended to use a CTG derived from the de-epithelialization of a free gingival graft.

The only difference is that in Class II, in the presence of adequate papillae dimension, the surgical treatment can be performed with the implant supported crown in situ while in Class III and IV it is necessary to remove the crown and perform the surgery on the abutment. In a Class IV it is suggested to perform the entire prosthetic surgical technique.
The prosthetic-surgical technique introduced by Zucchelli and coworkers ${ }^{29}$ is indicated for the treatment of the PSTDs with a minor interproximal bone loss and shallow papillae (subcategory b). This approach involves crown removal, change, or reduction of the abutment, providing shorter provisional crowns 2 months before the surgery to allow for maximum interproximal soft tissue growth in width and thickness. In this way the CAF + CTG can be performed by taking advantage of the augmented interproximal papillae that can be de-epithelialized on the occlusal surface towards the palate. After maturation and conditioning of the increased soft tissue with a new temporary crown, the definitive restoration can be provided 8 to 12 months after the surgery. This protocol has shown to be highly successful in treating STDs both in the short- and long-term ${ }^{29,38}$ with a mean dehiscence coverage of $96.3 \%$ and $99.2 \%$, at 1 and 5 years, respectively. The stability and the improvement in mean coverage is most likely due to the CTG maturation with time that results in an increased buccal soft tissue thickness $(1.54 \pm 0.21 \mathrm{~mm}$ at 1 year and 1.8 at 5 years). Additionally, the phenomenon of "creeping" may 
explain the improved mean coverage of the dehiscence at 5 years compared with the 1-year time point. ${ }^{38}$ The stability in the long-term results, together with the possibility of having a coronal migration of the soft tissue margin, further supports the benefits of using a CTG de-epithelialized from the palatal free gingival graft for the treatment of the PSTD.

When the height of at least one papilla is at the same level or more apical of the ideal position of the soft tissue margin of the implant-supported crown (subclass c), it is crucial to consider the position of the head of the implant with respect to the imaginary line connecting the adjacent gingival margin. Indeed, an implant head position within this line (Class IIIc) can be treated with a submerged approach. ${ }^{27,28}$ The goal of the surgery, in this case, is not only to cover the PSTD but also to improve the height of the deficient papilla/ae. The rationale behind this approach is to leave the soft tissue to cover the head of the implant as much as possible by removing the crown and the abutment and leaving only the cover screw. After 3 to 6 months, during which the patient is wearing a temporary Maryland bridge, the implant site can then be treated as an edentulous area with a soft tissue augmentation procedure and submerged healing. After the healing (6 months) a punch flapless procedure is used to expose the implant head, and subsequent to conditioning the augmented peri-implant soft tissue with a new temporary crown the final restoration is delivered. ${ }^{28}$ Among these procedures, the connective tissue platform technique has also been demonstrated to be effective in increasing both the apical-coronal and bucco-lingual dimensions of the soft tissue in a single edentulous area in one surgical procedure. ${ }^{6,41}$

Implant removal should be considered when, together with the lack of papilla/ae, the implant head is buccally displaced (Class IVc). ${ }^{31}$ Indeed, given the implant malpositioning, it is very likely that a Class IVc PSTD is also complicated by a deep buccal bone dehiscence that negatively affects the maintenance of the soft-tissue margins ${ }^{6}$ and therefore can negatively impair the outcomes of the surgery.

Bearing in mind that the treatment of PSTD is mainly guided by the patients' esthetic demands and that the final outcome is not only a complete dehiscence coverage but also a satisfactory esthetic outcome, the present article provides a classification of PSTDs strictly related to the possible surgical approaches for managing these complications. However, it should be mentioned that this classification is based on the clinical experience of the authors and therefore, future studies are needed to validate this proposal.

\section{5 | CONCLUSIONS}

The proposed classification describes four classes and three subcategories of soft tissue dehiscence/deficiencies at single implant sites based on the bucco-lingual position of the implant-supported crown (and the implant head) as well as the interproximal soft tissue dimensions and provides recommendations for selecting the most appropriate treatment protocol. Further studies are necessary to explore its validity.

\section{ACKNOWLEDGMENTS}

The authors do not have any financial interests, either directly or indirectly, in the products or information listed in the paper. This paper was partially supported by the University of Michigan Periodontal Graduate Student Research Fund. The authors report no conflicts of interest related to this study.

\section{ORCID}

Lorenzo Tavelli (1D https://orcid.org/0000-0003-4864-3964

Shayan Barootchi (D) https://orcid.org/0000-0002-5347-6577

Hom-Lay Wang (iD https://orcid.org/0000-0003-4238-1799

\section{REFERENCES}

1. Dierens M, Vandeweghe S, Kisch J, Nilner K, De Bruyn H. Longterm follow-up of turned single implants placed in periodontally healthy patients after 16-22 years: radiographic and peri-implant outcome. Clin Oral Implants Res. 2012;23:197-204.

2. Quirynen M, Herrera D, Teughels W, Sanz M. Implant therapy: 40 years of experience. Periodontol 2000. 2014;66:7-12.

3. De Bruyn H, Raes S, Matthys C, Cosyn J. The current use of patient-centered/reported outcomes in implant dentistry: a systematic review. Clin Oral Implants Res. 2015;26 Suppl 11: 45-56.

4. Buser D, Sennerby L, De Bruyn H. Modern implant dentistry based on osseointegration: 50 years of progress, current trends and open questions. Periodontol 2000. 2017;73:7-21.

5. Roccuzzo M, Gaudioso L, Bunino M, Dalmasso P. Surgical treatment of buccal soft tissue recessions around single implants: 1year results from a prospective pilot study. Clin Oral Implants Res. 2014;25:641-646.

6. Mazzotti C, Stefanini M, Felice P, Bentivogli V, Mounssif I, Zucchelli G. Soft-tissue dehiscence coverage at peri-implant sites. Periodontol 2000. 2018;77:256-272.

7. Bengazi F, Wennstrom JL, Lekholm U. Recession of the soft tissue margin at oral implants. A 2-year longitudinal prospective study. Clin Oral Implants Res. 1996;7:303-310.

8. Small PN, Tarnow DP, Cho SC. Gingival recession around widediameter versus standard-diameter implants: a 3- to 5-year longitudinal prospective study. Pract Proced Aesthet Dent. 2001;13: 143-146.

9. Lin GH, Chan HL, Wang HL. The significance of keratinized mucosa on implant health: a systematic review. J Periodontol. 2013;84:1755-1767.

10. Chen ST, Buser D. Esthetic outcomes following immediate and early implant placement in the anterior maxilla-a systematic review. Int J Oral Maxillofac Implants. 2014;29 Suppl:186-215.

11. Cosyn J, Eghbali A, Hermans A, Vervaeke S, De Bruyn H, Cleymaet R. A 5-year prospective study on single immediate implants in the aesthetic zone. J Clin Periodontol. 2016;43:702-709. 
12. Buser D, Chappuis V, Belser UC, Chen S. Implant placement post extraction in esthetic single tooth sites: when immediate, when early, when late. Periodontol 2000. 2017;73:84-102.

13. Evans CD, Chen ST. Esthetic outcomes of immediate implant placements. Clin Oral Implants Res. 2008;19:73-80.

14. Cosyn J, Sabzevar MM, De Bruyn H. Predictors of inter-proximal and midfacial recession following single implant treatment in the anterior maxilla: a multivariate analysis. J Clin Periodontol. 2012;39:895-903.

15. Cosyn J, Hooghe N, De Bruyn H. A systematic review on the frequency of advanced recession following single immediate implant treatment. J Clin Periodontol. 2012;39:582-589.

16. Fu JH, Su CY, Wang HL. Esthetic soft tissue management for teeth and implants. J Evid Based Dent Pract. 2012;12:129-142.

17. Sculean A, Gruber R, Bosshardt DD. Soft tissue wound healing around teeth and dental implants. J Clin Periodontol. 2014;41 Suppl 15:S6-22.

18. Sculean A, Chappuis V, Cosgarea R. Coverage of mucosal recessions at dental implants. Periodontol 2000. 2017;73:134-140.

19. Burkhardt R, Joss A, Lang NP. Soft tissue dehiscence coverage around endosseous implants: a prospective cohort study. Clin Oral Implants Res. 2008;19:451-457.

20. Miller PD, Jr. A classification of marginal tissue recession. Int $J$ Periodontics Restorative Dent. 1985;5(2):8-13.

21. Cairo F, Nieri M, Cincinelli S, Mervelt J, Pagliaro U. The interproximal clinical attachment level to classify gingival recessions and predict root coverage outcomes: an explorative and reliability study. J Clin Periodontol. 2011;38:661-666.

22. Anderson LE, Inglehart MR, El-Kholy K, Eber R, Wang HL. Implant associated soft tissue defects in the anterior maxilla: a randomized control trial comparing subepithelial connective tissue graft and acellular dermal matrix allograft. Implant Dent 2014;23:416-425.

23. Happe A, Stimmelmayr M, Schlee M, Rothamel D. Surgical management of peri-implant soft tissue color mismatch caused by shinethrough effects of restorative materials: one-year follow-up. Int $J$ Periodontics Restorative Dent. 2013;33:81-88.

24. Lee CT, Hamalian T, Schulze-Spate U. Minimally invasive treatment of soft tissue deficiency around an implant-supported restoration in the esthetic zone: modified VISTA technique case report. $J$ Oral Implantol. 2015;41:71-76.

25. Fickl S. Peri-implant mucosal recession: clinical significance and therapeutic opportunities. Quintessence Int. 2015;46:671-676.

26. Le B, Borzabadi-Farahani A, Nielsen B. Treatment of labial soft tissue recession around dental implants in the esthetic zone using guided bone regeneration with mineralized allograft: a retrospective clinical case series. J Oral Maxillofac Surg. 2016;74:1552-1561.

27. Lai YL, Chen HL, Chang LY, Lee SY. Resubmergence technique for the management of soft tissue recession around an implant: case report. Int J Oral Maxillofac. 2010;25:201-204.

28. Chu SJ, Tarnow DP. Managing esthetic challenges with anterior implants. Part 1: midfacial recession defects from etiology to resolution. Compend Contin Educ Dent. 2013;34 Spec No 7:26-31.

29. Zucchelli G, Mazzotti C, Mounssif I, Mele M, Stefanini M, Montebugnoli L. A novel surgical-prosthetic approach for soft tissue dehiscence coverage around single implant. Clin Oral Implants Res. 2013;24:957-962.

30. Berglundh T, Armitage G, Araujo MG, et al. Peri-implant diseases and conditions: consensus report of workgroup 4 of the 2017 World
Workshop on the classification of periodontal and peri-implant diseases and conditions. J Clin Periodontol. 2018;45 Suppl 20:S286-S291.

31. Butler B, Kinzer GA. Managing esthetic implant complications. Compend Contin Educ Dent. 2012;33:514-518.

32. Cairo F, Nieri M, Pagliaro U. Efficacy of periodontal plastic surgery procedures in the treatment of localized facial gingival recessions. A systematic review. J Clin Periodontol. 2014;41 Suppl 15: S44-62.

33. Tavelli L, Barootchi S, Nguyen TV, Tattan M, Ravida A, Wang HL. Efficacy of tunnel technique in the treatment of localized and multiple gingival recessions: a systematic review and a meta-analysis. J Periodontol. 2018;89(9):1075-1090.

34. Decker AM, Suarez-Lopez Del Amo F, Urban IA, Miller PD, Jr, Wang HL. Prognostic classification system for implant recession defects. Implant Dent. 2017;26:848-852.

35. Dierens M, de Bruecker E, Vandeweghe S, Kisch J, de Bruyn H, Cosyn J. Alterations in soft tissue levels and aesthetics over a 1622 year period following single implant treatment in periodontallyhealthy patients: a retrospective case series. J Clin Periodontol. 2013;40:311-318.

36. Jung RE, Sailer I, Hammerle CH, Attin T, Schmidlin P. In vitro color changes of soft tissues caused by restorative materials. Int $J$ Periodontics Restorative Dent. 2007;27:251-257.

37. van Brakel R, Noordmans HJ, Frenken J, de Roode R, de Wit GC, Cune MS. The effect of zirconia and titanium implant abutments on light reflection of the supporting soft tissues. Clin Oral Implants Res. 2011;22:1172-1178.

38. Zucchelli G, Felice P, Mazzotti C, et al. 5-year outcomes after coverage of soft tissue dehiscence around single implants: a prospective cohort study. Eur J Oral Implantol. 2018;11:215-224.

39. Schallhorn RA, McClain PK, Charles A, Clem D, Newman MG. Evaluation of a porcine collagen matrix used to augment keratinized tissue and increase soft tissue thickness around existing dental implants. Int J Periodontics Restorative Dent. 2015;35:99-103.

40. Zucchelli G, Mazzotti C, Mounssif I, Marzadori M, Stefanini M. Esthetic treatment of peri-implant soft tissue defects: a case report of a modified surgical-prosthetic approach. Int J Periodontics Restorative Dent. 2013;33:327-335.

41. Zucchelli G, Mazzotti C, Bentivogli V, Mounssif I, Marzadori M, Monaco C. The connective tissue platform technique for soft tissue augmentation. Int J Periodontics Restorative Dent. 2012;32: 665-675.

\section{SUPPORTING INFORMATION}

Additional supporting information may be found online in the Supporting Information section at the end of the article.

How to cite this article: Zucchelli G, Tavelli L, Stefanini M, et al. Classification of facial peri-implant soft tissue dehiscence/deficiencies at single implant sites in the esthetic zone. J Periodontol. 2019;90:11161124. https://doi.org/10.1002/JPER.18-0616 